\title{
Geosystems as an alternative to conventional coastal defense
}

\author{
A.I. Antón, J.L. Almazán, A. Lechuga, J.M. de la Peña
}

Centre for Harbours and Coastal Studies, CEDEX, Antonio López 81, Madrid, 28026, Spain

\section{ana.i.anton@cedex.es}

Research Group on Marine, Coastal and Port Environment and other Sensitive Areas, Universidad Politécnica de Madrid, Profesor Aranguren s/n, Madrid 28040, Spain

joseluis.almazan@upm.es

Centre for Harbours and Coastal Studies, CEDEX, Antonio López 81, Madrid, 28026, Spain

antonio.lechuga@cedex.es

Centre for Harbours and Coastal Studies, CEDEX, Antonio López 81, Madrid, 28026, Spain

jose.m.pena@cedex.es

\begin{abstract}
In recent decades, the increase in population on the coast, growth of erosion in many coastal stretches and the sea level rise, due to climate change, have led governments to invest more in protecting the coast. Geosystems have been shown as an alternative to conventional coastal structures because of cost reduction, efficiency of construction and speed of implementation. However this alternative leads to increase knowledge in their behavior, design and durability by the lack of suitable materials to withstand large storms, high diversity of non-standard methods or techniques and ease of degradation by vandalism.
\end{abstract}

\section{Indexing terms/Keywords}

Gesystems, geotextile bags, geotextile tubes and geotextile containers.

\section{Academic Discipline And Sub-Disciplines}

Natural sciences and Earth sciences.

\section{SUBJECT CLASSIFICATION}

Coastal defense.

\section{TYPE (METHOD/APPROACH)}

Literary Analysis.

\section{Council for Innovative Research}

Peer Review Research Publishing System

\section{Journal of Advances in Natural Sciences}

Vol .3, No.1.

\section{http://www.cirins.com,}




\section{INTRODUCTION}

Geotextile-encapsulated sand elements are three-dimensional systems manufactured from geotextile materials filled with sand.They form a sub-group part of a wider system of geosynthetic solutions for erosion control which are known as Geosystems.There are three different types of elements, namely geotextile bags, geotextile tubes and geotextile containers. These elements are used in coastal engineering structures such as groins and breakwaters as an alternative to rubble mound quarry stone e.g. as core material. The main purpose of this paper is to analyze geosystems as a reliable alternative for conventional defense.

\section{LITERATURE REVIEW}

Some of the main studies developed for different applications of the geosynthetic materials have been: Liu (1981) presented an equation to describe the equilibrium shape of the geotextile tubes. Kobayashi and Jacobs (1985) investigated experimentally the stability of sandbags placed on nonuniform shapes. Pilarczyk (1996) concluded that, for shoreline protection, groins comprised of sand-filled geosynthetic bags serve as very reasonable alternatives to other conventional structures. Gutman (1979) also addressed sand-filled bags being used for revetments. Leshchinsky et al. (1996) discussed the design and manufacturing of geosynthetic tubes based on shape and tensión. Plaut and Klusman (1999) analyzed the stacking of tubes which implied large simplifications. And Pilarczyk (2000) presented a book about geosystems used for coastal and shoreline structures.

Oumeraci et al. (2003) carried out physical model investigations to establish a reliable stability formula for sand containers applied as dune protection under to storm waves. Recio-Molina and Yasuhara (2005) analyzed geometry of geotextile wrap-around revetments (GWR) using small-scale model test. Lawson (2008) reviewed the three main types of geosystems. Chu et al. (2011) presented a study about different applications of geotextile tubes. And Bezuijen and Pilarczyk (2012) described two applications of geotextiles in coastal defense.

\section{GEOTEXTILE-ENCAPSULATED SAND ELEMENTS}

There are three fundamental types of geotextile-encapsulated sand elements namely geotextile bags, geotextile tubes and geotextile containers, differentiated by geometrical shape and volume.

\subsection{Geotextile bags}

Geotextile bags are smaller volume containers filled with sand, placed on land either near water or below water. Are manufactured in a range of shapes, and they are installed in differents arrangement that greatly improves their overall stability and performance of the structure. Nowadays, geotextile bags range in volume from $0.05 \mathrm{~m}^{3}$ to around $5 \mathrm{~m}^{3}$, and may be pillow-shaped, box-shaped or mattress-shaped, depending on the required application.

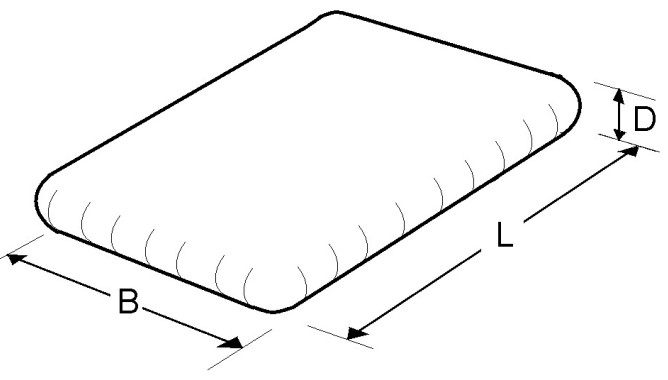

(3D)

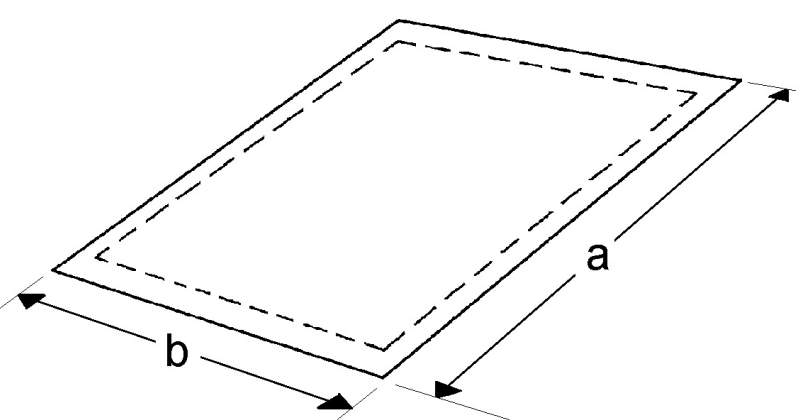

(2D)

Fig 1: General dimensions of box-shaped geotextile bagsfull and empty

\subsection{Geotextile tubes}

Geotextile tubes are tubular containers that are filled with sand in situ, on land or in water. Are placed and filled on site with the required geometrical form. Sand is filled by hydraulically pumping into the tube. Geotextile tubes range in size from $1 \mathrm{~m}$ to $10 \mathrm{~m}$ in diameter, and can have about $200 \mathrm{~m}$ in maximum length. 
Geotextile tubes

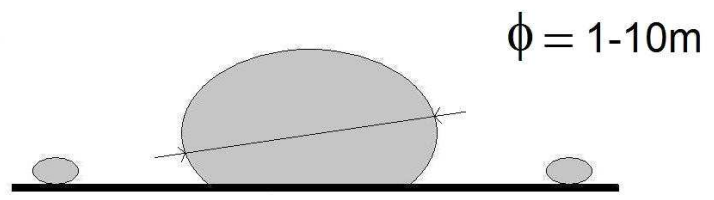

Geotextile containers

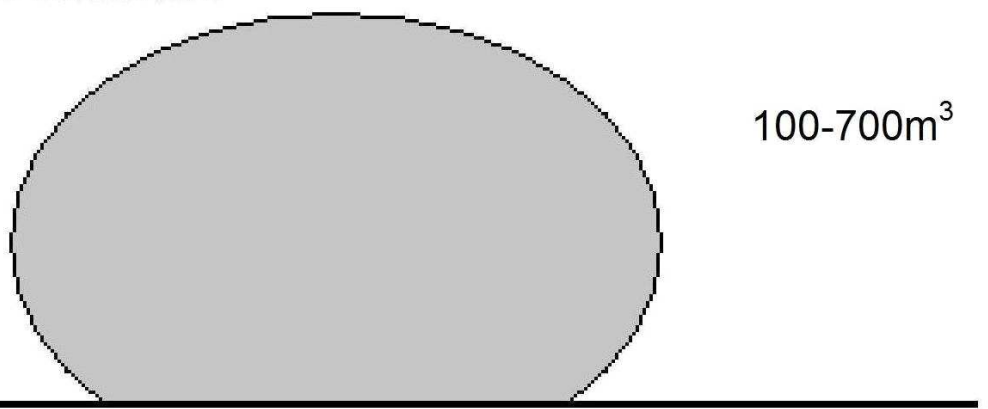

Fig 2: Shape and dimensions of geotextile tubes and geotextile containers

\subsection{Geotextile containers}

Geotextile containers are large-volume elements that are filled in barges above water, then are positioned and are dropped at deep water. The volumes of these containers more commonly range from $100 \mathrm{~m} 3$ to $700 \mathrm{~m} 3$, although containers as large as $1.000 \mathrm{~m} 3$ have been installed. To facilitate the installation of geotextile containers of this magnitude, must be utilized an efficient and practical installation system . Today, this has been accomplished by means of split-bottom barges.

\section{COASTAL APPLICATIONS OF GEOTEXTILE-ENCAPSULATED SAND ELEMENTS}

The main coastal applications are divided by revetments, seawalls, slope buttressing, scour prevention, groins, breakwaters and finally artificial reefs.

\subsection{Revetments}

Revetments are onshore structures to protect the natural sloping shoreline from erosion. They can be located relative to the shoreline: dry beach or in shallow water. In the first case it would have to be designed to withstand the pounding of the surf extreme periods with a relative incidence of the wave energy, while in the second case the structure must support the continued wave action in normal time. Geotextile bags and geotextile tubes are used for revetment structures. To prevent erosion of the foundation soil at a toe of the revetment, it is common practice to extend the bottom layer of geotextile bags.

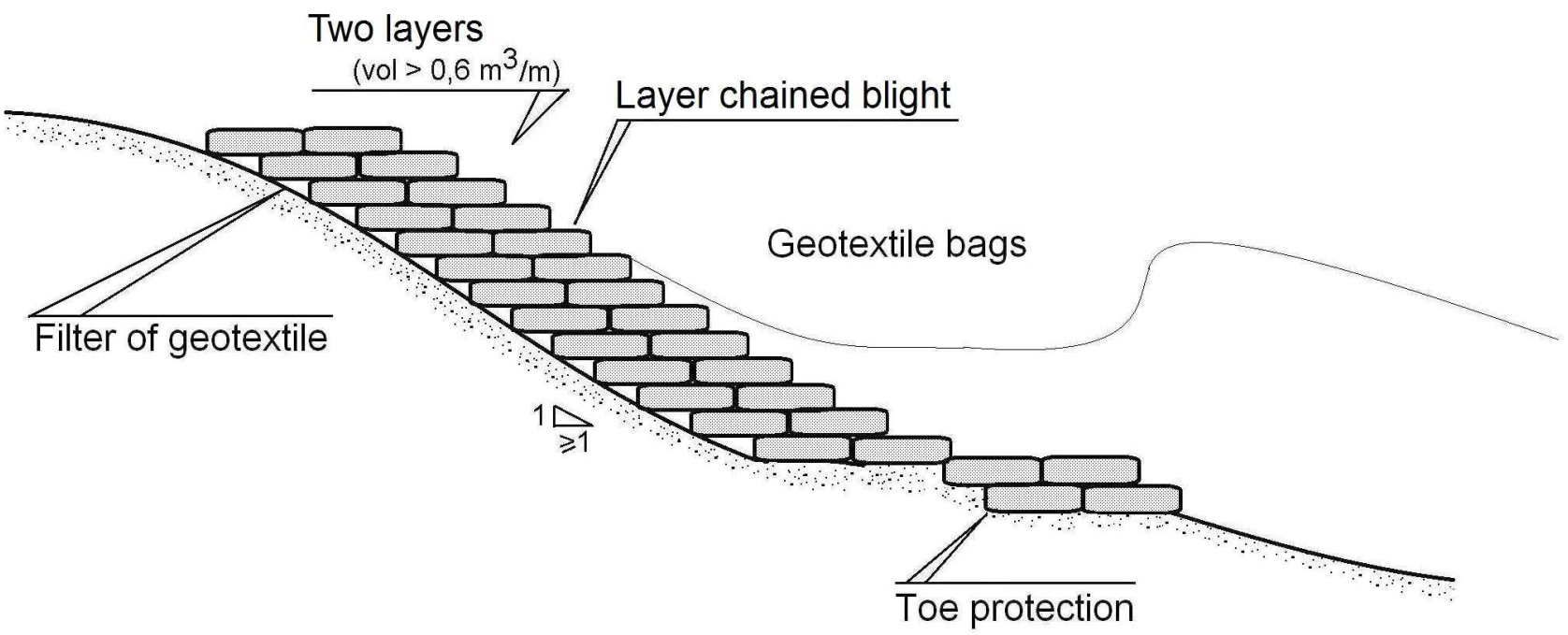

Fig 3: Revetment with geotextile bags for erosion 


\subsection{Seawalls}

Seawalls made of geotextile bags or geotextile tubes filled with sand have basically two differences between revetments structures made with the same elements, one of them is the slope of the structure, close to the vertical, and the other one is that must bear the earth pressure. Seawalls are stronger than revetments and must to have two lines of geotextile bags joined, at least.

Their effects and behavior are similar to the wall of the conventional beaches. And both the top and the toe of the structure should be protected to avoid scour.

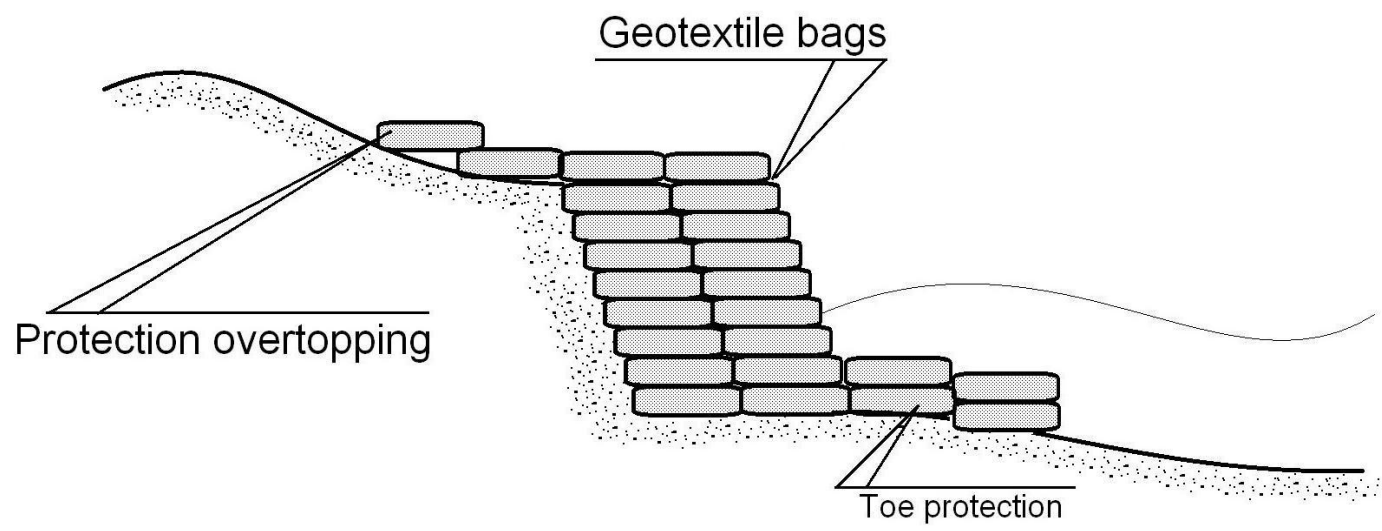

Fig 4: Seawall of geotextile bags filled with sand

\subsection{Slope buttressing}

As with geotextile containers, geotextile bags can be used to provide buttress support to an unstable slope in a hydraulic environment. Here, geotextile bags act as a mass-gravity structure, providing additional restraint to the toe of the unstable slope.

One advantage of geotextile bags is that can be installed at shallow water depths if is necessary, unlike geotextile containers, which have to be installed at relatively greater water depth (Lawson 2008).

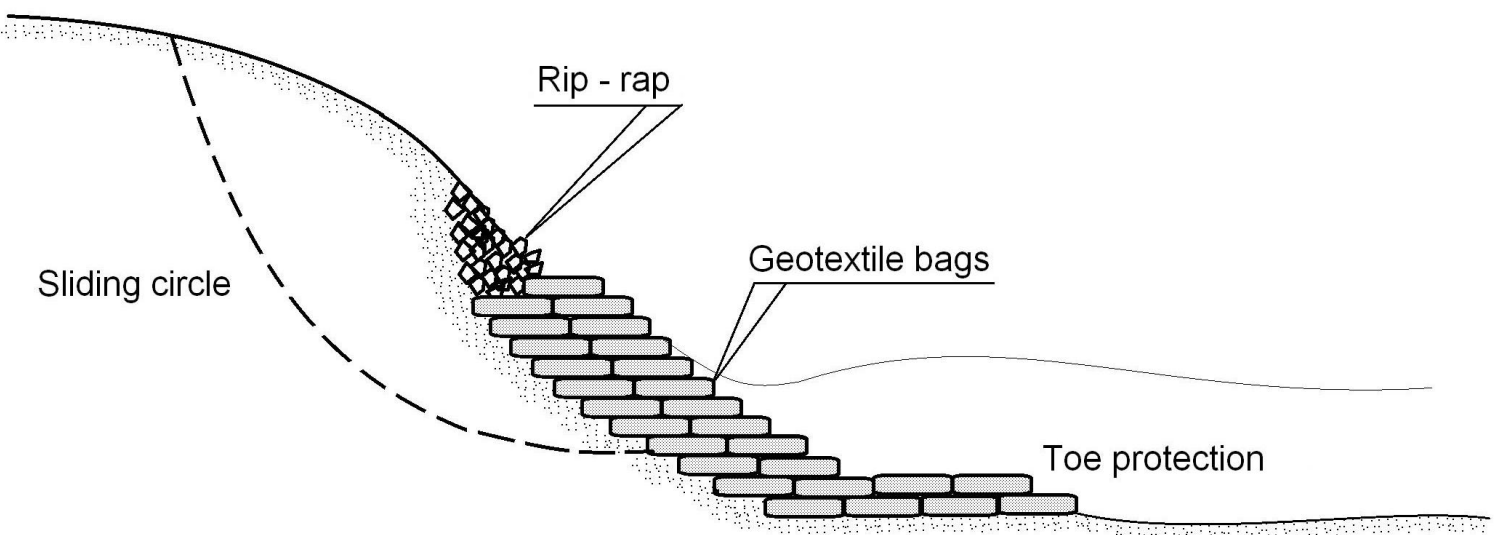

Fig 5: Geotextile bags as slope buttressing

\subsection{Scour prevention}

Geotextile bags are used as expedient means of scour prevention to prevent undermining of nearby structures. This is the original application for these units. Geotextile bags can be easily installed using simple machinery. The bags conform to the shape of the scour hole, and thus provide good sealing qualities. An example of use is given by Heibaum (1999).

Interaction between waves and a vertical or nearly vertical wall on a beach tends to form a scour in the toe of the wall. The geotextile bags filled with sand can be used to avoid this scour.

The arrangement of the bags should be such that fill the volume would be formed if there were not available this additional work. 


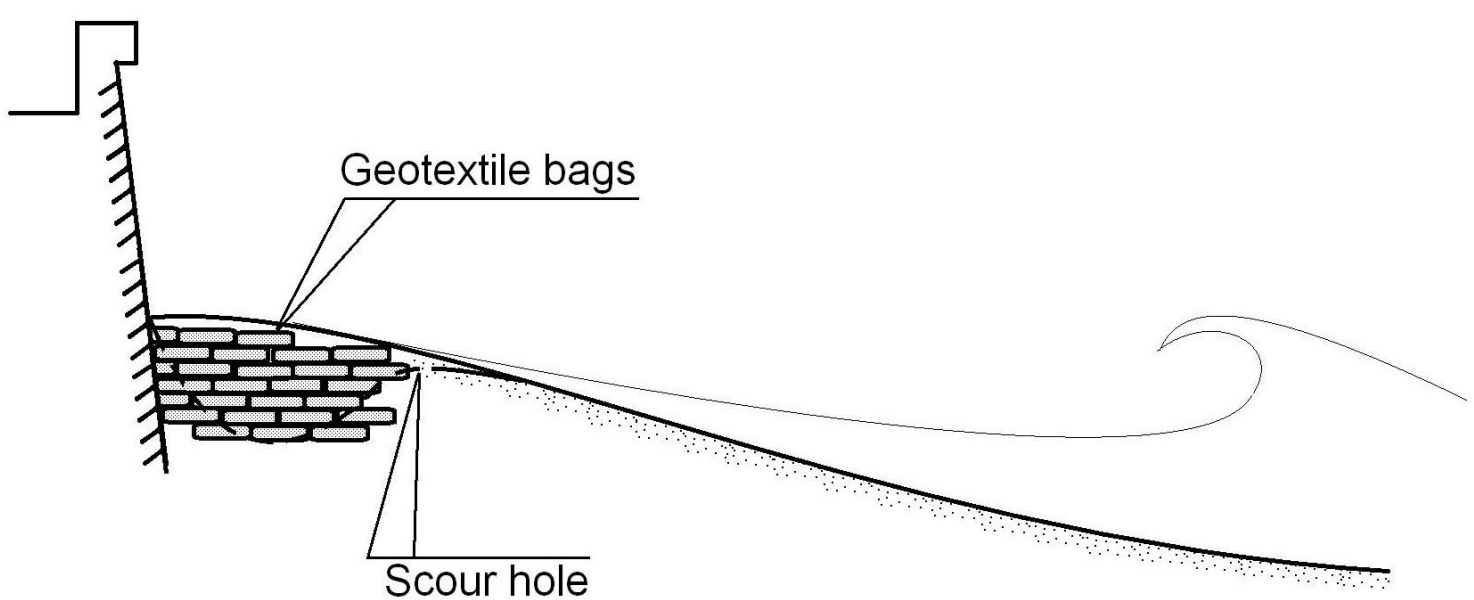

Fig 6: Geotextile bags to prevent scour

\subsection{Groins}

Groins are structures more or less perpendicular to the coastline. The aim of groins is to protect shore from erosion due to long shore currents and/or to trap sediments from the natural littoral transport, which leads to sand accretion between the groins.

Geotextile bags may be used as groins to prevent the shoreline movement of sediment. Here, the same conditions apply for geotextile bags as for geotextile tubes.

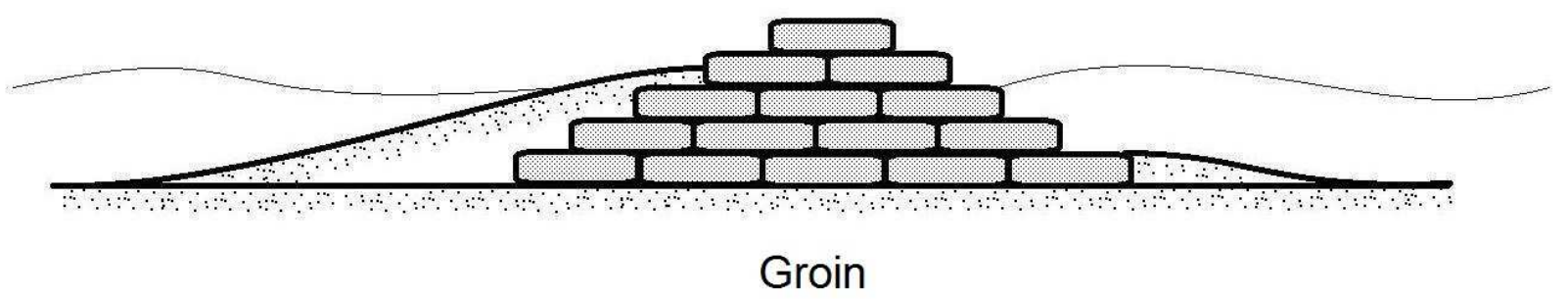

Fig 7: Geotextile bags as groin to erosion control

\subsection{Breakwaters and artificial reefs}

Breakwaters are structures constructed on coasts to shelter coastlines, harbor entrances and water intakes against waves and currents or as a control to avoid beach erosion.

Offshore breakwaters reduce the intensity of wave action in shore waters and thereby reduce coastal erosion. They are constructed some distance away from the coast or built with one end linked to the coast. A breakwater structure is designed to absorb the energy of the waves that hit it.

The objectives of artificial reefs can include:

- Protection against major storm events by intercepting wave energy.

- Widening of the beach and dunes to provide additional open space.

- And improving surfing conditions.

These objectives of artificial reefs can be achieved through the construction of an artificial reef, combined with sand nourishment works or other measures where appropriate. Artificial reefs may reduce natural reef usage, provide corridors for marine species to move between previously unconnected habitats and provide slid structures in areas that were previously sandy or soft bottomed. 


\section{FORMULAE OF STABILITY FOR GEOTEXTILE BAGS}

The design of structures which are constructed using geotextile bags is complicated. Stability equations for the armor layer and for the entire structure, which are used for designs of structures built with rock or armor units, cannot simply be transferred to design of geotextile bags (PIANC 2011).

This section aims at giving a summary of the increased knowledge, especially that concerning the stability criteria for geotextile bags.

\subsection{Formula of stability according to Pilarczyk (1996)}

He concluded that the stability of geotextile bags filled with sand, with the width-length ratio not larger than 1 to 3 and properly filled (> 70\%), can be computed in the similar way as riprap. And he recommended calculate the stability according to Pilarczyk's formula (Pilarczyk, 1990):

$$
\frac{\mathrm{H}_{\mathrm{S}}}{\Delta \mathrm{D}}=\cos \alpha \xi^{-1 / 2} \quad(\text { for } \xi \leq 3)
$$

For $\xi>3$, the values calculated for $\xi=3$ can be used,

Where: $\mathrm{Hs}=$ significant wave height $[\mathrm{m}], \Delta=(\rho \mathrm{s}-\rho \mathrm{w}) / \rho \mathrm{w}=$ relative density of the bags $[-], \mathrm{D}=$ average thickness of bags $[\mathrm{m}], \mathrm{c}=$ stability coefficient defined at $\xi=1,(\mathrm{c}=2.5)$, $\cos \alpha=$ slope angle [-], (it can be neglected for slopes milder than 1 on 3), $\xi=\tan \alpha /(\mathrm{Hs} / \mathrm{Lo}) 1 / 2=$ surf-similarity parameter [-] and Lo = wave length [m]. The density of bags ( $\rho$ s) can be assumed 2000 and $2300 \mathrm{~kg} / \mathrm{m} 3$ resp. for sand and concrete ( $\Delta$ resp. 1 and 1.3).
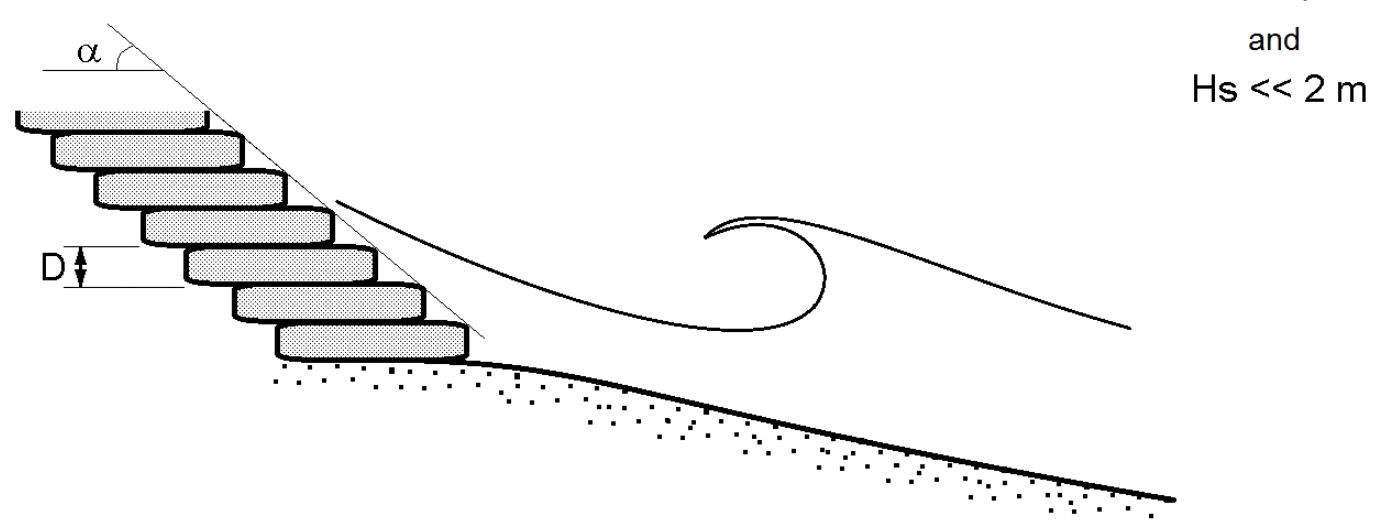

Fig 8: Variables of the stability formula of geotextile bags according to Pilarczyk (1996)

\subsection{Formula of stability according to Wouters (1998)}

A new stability formula, based on previous experimental data, was proposed by Wouters (1998). This formula was taken into account in different documents published, including Dassanayake (2013), and was referenced by the stability number, as a way to give continuity to calculate stability dikes. It was determined for revetments:

$$
\mathrm{N}_{S}=\frac{\mathrm{H}_{\mathrm{S}}}{\left(\frac{\rho_{E}}{\rho_{W}}-1\right) D_{50}}=\frac{C_{W}}{\sqrt{\xi_{0}}}
$$

Where: $\mathrm{Ns}=$ stability number [-], $\mathrm{Hs}=$ incident significant wave height [m], $\rho_{E}=$ density of geotextile bag [kg/m3], defined as: $\rho_{E}=(1-n) \cdot \rho_{s}+\rho_{w} \cdot n, n=$ porosity of filling material $[-], \rho_{w}=$ density of water $[\mathrm{kg} / \mathrm{m} 3], D_{50}=$ thickness of armor layer [m], $\mathrm{Cw}=$ empirical parameter derived from the stability number $\mathrm{Ns}[-], \xi_{0}=\tan \alpha /(\mathrm{Hs} / \mathrm{L}) 1 / 2=$ Iribarren number $[-]$, $\alpha=$ slope angle of the structure $\left({ }^{\circ}\right), \mathrm{Lo}=\mathrm{g} \mathrm{T} 2 /(2 \pi)=$ deep water wave length using $\mathrm{Tp}[\mathrm{m}]$. 


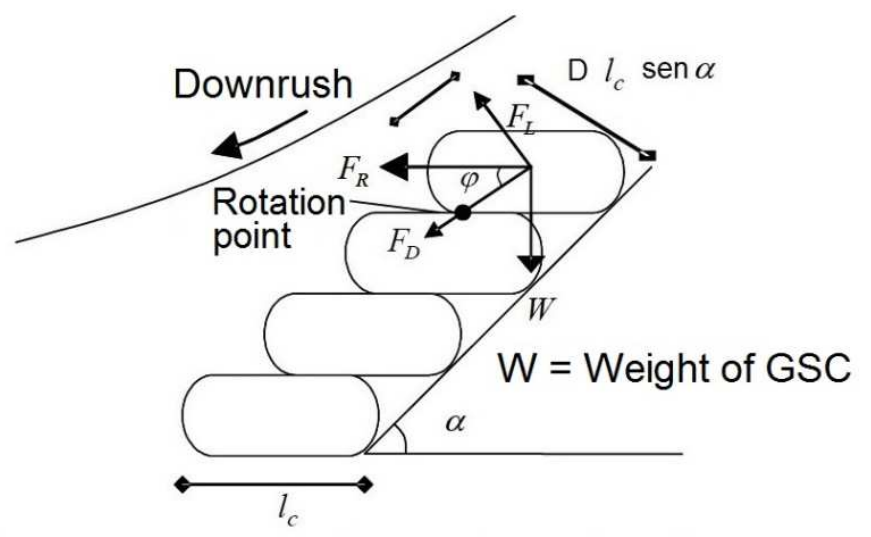

$F_{R}=$ Resultant force $\quad F_{D}=$ Drag force $\quad F_{L}=$ Lift force

Fig 9: Parameters used in the stability formula of geotextile bags according to Wouters (1998)

\subsection{S Formulae of stability according to Oumeraci et al. (2003)}

These formulae are similar to before one, presented by Wouters (1998), using the number of stability. However two stability formulae were obtained based on data, in laboratory and in a large channel.

- The formula obtained for the slope elements was:

$$
\mathrm{N}_{\mathrm{s}, \text { slope }}=\frac{\mathrm{H}_{\mathrm{S}}}{\left(\frac{\rho_{\mathrm{E}}}{\rho_{\mathrm{W}}}-1\right) \mathrm{D}}=\frac{2.75}{\sqrt{\xi_{0}}}
$$

Where: $D=$ characteristic diameter of geotextile sand container defined as $D=\mid \sin \alpha$, $l=$ length of sand container [m] (container dimension in wave direction).

- The formula obtained for the crest elements was:

$$
\mathrm{N}_{\mathrm{s}, \text { crest }}=\frac{\mathrm{H}_{\mathrm{S}}}{\left(\frac{\rho_{\mathrm{E}}}{\rho_{\mathrm{W}}}-1\right) \mathrm{D}}<0.79+0.09 \frac{\mathrm{R}_{\mathrm{C}}}{\mathrm{H}_{\mathrm{S}}}
$$

Where: $\mathrm{Rc}=$ freeboard $[\mathrm{m}]$.

\subsection{Formulae of stability according to Recio and Oumeraci (2009)}

They were based on considering two basic types of faults in a structure, like: overturning and sliding. Coefficients of the new formula were found by performing various trials on reduced model.

Calculation formulations of the structure are as follows bags, replacing the volume data and the projection areas, based on the length of the bag ( Ic), the width of the bag ( $1 / 2 \mathrm{Ic})$ and the height of the bag $(1 / 5 \mathrm{lc})$.

- Without considering deformation (for sliding):

$$
\begin{gathered}
\mathrm{l}_{\mathrm{c}} \geq \mathrm{u}^{2} \frac{\left(0.5 \mathrm{C}_{\mathrm{D}}+2.5 \mathrm{C}_{\mathrm{L}} \mu\right)}{\left(\mu \Delta \mathrm{g}-\mathrm{C}_{\mathrm{M}} \frac{\partial \mathrm{U}}{\partial \mathrm{t}}\right)} \\
\Delta=\frac{\rho_{\mathrm{S}}}{\rho_{\mathrm{W}}}-1
\end{gathered}
$$


Considering deformation (for sliding):

$$
l_{c \text { (sliding) }} \geq \mathrm{u}^{2} \frac{\left(0.5 \mathrm{KS}_{\mathrm{CD}} \mathrm{C}_{\mathrm{D}}+2.5 \mathrm{KO}_{\mathrm{CL}} \mathrm{C}_{\mathrm{L}} \mu\right)}{\left(\mu \mathrm{KS}_{\mathrm{R}} \Delta \mathrm{g}-\mathrm{KS}_{\mathrm{CM}} \mathrm{C}_{\mathrm{M}} \frac{\partial \mathrm{U}}{\partial \mathrm{t}}\right)}
$$

Considering deformation (for overturning):

$$
\mathrm{l}_{\mathrm{c} \text { (overturning) }} \geq \mathrm{u}^{2} \frac{\left(0.05 \mathrm{KO}_{\mathrm{CD}} \mathrm{C}_{\mathrm{D}}+1.25 \mathrm{KO}_{\mathrm{CL}} \mathrm{C}_{\mathrm{L}} \mu\right)}{\left(0.5 \mathrm{KO}_{\mathrm{R}} \Delta \mathrm{g}-0.1 \mathrm{KO}_{\mathrm{CM}} \mathrm{C}_{\mathrm{M}} \frac{\partial \mathrm{U}}{\partial \mathrm{t}}\right)}
$$

Where: $\rho s=$ density of bag $[\mathrm{kg} / \mathrm{m} 3]$, $\rho w=$ density of water $[\mathrm{kg} / \mathrm{m3}]$. And CD, CL, CM, KSCD, KOCL, KOCD, KOR and $\mathrm{KOCM}$ are coefficient factors.

\subsection{Formula of stability according to Dassanayake (2013)}

New stability formula was developed based on recent and past experimental investigations and numerical simulations. This let to determine the following conclusions:

- $\quad$ Geotextile sand container $100 \%$ filled are more stable than geotextile sand container $80 \%$ filled.

- Development of the damage is important for a comprehensive quantification of the effect of the interface friction between the geotextile sand containers on the hydraulic stability.

- Hydraulic stability can be increased by changing the inclination angle of geotextile sand container in the construction process.

$$
\mathrm{N}_{\mathrm{S}} \sqrt{\xi_{\mathrm{O}}}=\mathrm{A}\left(\frac{\mathrm{R}_{\mathrm{C}}}{\mathrm{H}} \cdot \frac{1}{\xi_{\mathrm{O}}}\right)^{2}+\mathrm{B}\left(\frac{\mathrm{R}_{\mathrm{C}}}{\mathrm{H}} \cdot \frac{1}{\xi_{\mathrm{O}}}\right)+\mathrm{C}
$$

Where:

$\mathrm{N}_{\mathrm{S}}=\frac{\mathrm{H}_{\mathrm{S}}}{\left(\left(\rho_{\mathrm{GSC}} / \rho_{\mathrm{W}}\right)-1\right) \mathrm{l}_{\mathrm{c}} \sin \alpha}$

$\xi_{\mathrm{o}}=\frac{\tan \alpha}{\sqrt{\mathrm{H} / \mathrm{L}_{\mathrm{O}}}}$

A, B, C = empirical parameters depending on the type of geotextile material and the sand fill ratios [-], $\mathrm{H}=\mathrm{H}_{m}$ for regular wave tests or $\mathrm{H}_{2 \%}$ for irregular wave tests [m], $\mathrm{Hm}=$ incipient mean wave height from regular wave tests measured at intermediate water depth (at the beginning of the foreshore slope) [m], $\mathrm{H}_{2 \%}=$ mean of highest $2 \%$ of the incident waves in a time series (mean of the highest 20 incident waves from the wave reflection analysis of 1000 waves and for a Rayleigh distribution the values $\mathrm{H}_{2} \%=1.4 \mathrm{Hs}$ ) [m], $\mathrm{Rc}=$ crest free board [m], Lo = wave length at deep water, $\mathrm{Ns}=$ stability number $[-], \rho_{w}=$ density of water $\left[\mathrm{Kg} / \mathrm{m}^{3}\right], \rho_{\mathrm{GSC}}=$ density of GSCs $\left[\mathrm{Kg} / \mathrm{m}^{3}\right], \mathrm{I}_{\mathrm{c}}=$ length of GSC $[\mathrm{m}], \alpha=$ slope angle of the structure $[0]$, Lo $=g \cdot T^{2} /(2 \pi)=$ deep water wave length calculated using the mean wave period $[\mathrm{m}]$.

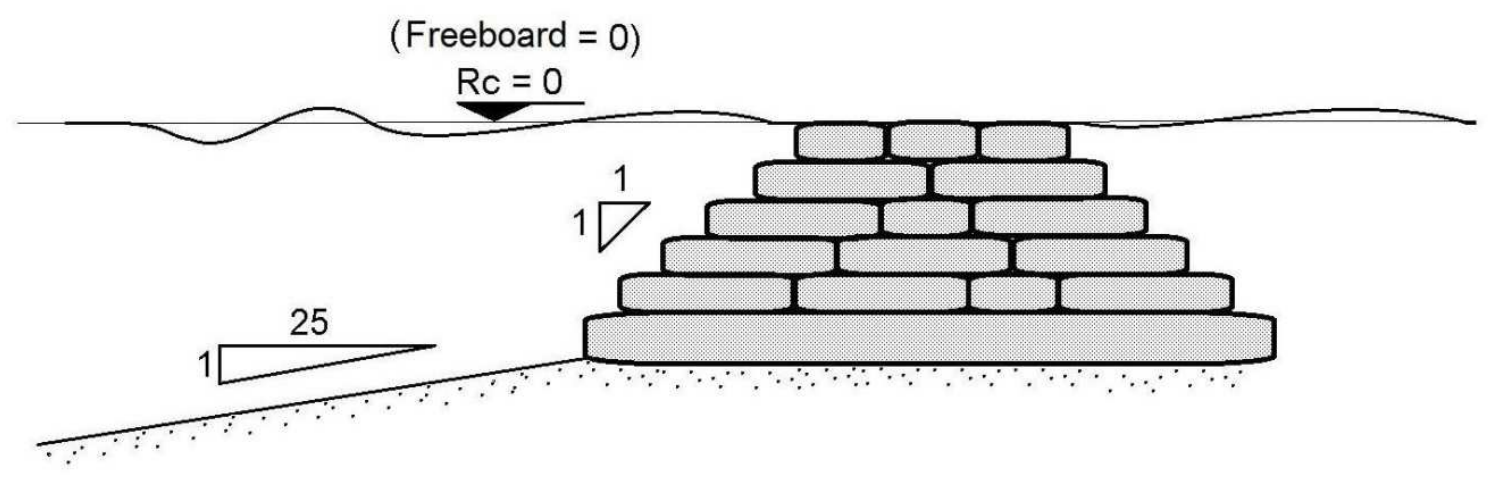

Fig 10: Section structure tested by Dassanayake (2013) 


\section{FORMULAE OF STABILITY FOR GEOTEXTILE TUBES}

Design methods have been published based on the results of many reduced scale tests. However, the failure mechanisms that lead to the instability of the tubes are complicated and have not yet led to a generic approved design method, (PIANC 2011).

All stability formulae used are for geotextile tubes placed perpendicular to the wave direction.

\subsection{Formula of stability according to Pilarczyk (2000)}

A theoretical derivation of the stability of a stacked geotextile tube with the crest at the SWL was done on the results obtained from a study undertaken on the stability of sand and mortar filled geotextile tubes and geotextile containers for Nicolon by DelfHidraulics (1994). It was concluded that the critical wave height was equal to the theoretical diameter of the tube. A reduction of the wave period, flattening of the tube and reducing the water level were found to have a positive effect on the stability.

- $\quad$ Overturning moment (per m length):

$$
\mathrm{M}_{\mathrm{O}}=\frac{3}{4}(1+\mathrm{k}) \mathrm{H} \frac{1}{2} \mathrm{~h}_{1}^{2} \rho_{\mathrm{w}} \mathrm{g}
$$

- $\quad$ Restoring moment (per m length):

$$
\mathrm{M}_{\mathrm{R}}=\mathrm{A}\left(\rho_{\mathrm{S}}-\rho_{\mathrm{W}}\right) \mathrm{g} \frac{1}{2} \mathrm{~b}
$$

Where: $\mathrm{k}=$ reflection coefficient $(\mathrm{k}=0.45), \mathrm{Hs}=$ wave height $[\mathrm{m}], \mathrm{h}_{1}=$ height of tube $[\mathrm{m}], \rho_{\mathrm{w}}=$ density of water $\left[\mathrm{kg} / \mathrm{m}^{3}\right], \mathrm{g}=$ acceleration by gravity $\left[\mathrm{m} / \mathrm{s}^{2}\right], A=$ area of tube cross section $\left[\mathrm{m}^{2}\right], \rho_{\mathrm{s}}=$ density of saturated sand $\left[\mathrm{kg} / \mathrm{m}^{3}\right], b=$ tube width $[\mathrm{m}]$.

- $\quad$ To maintain static equilibrium:

$$
\mathrm{H}<\frac{4}{3} A b \frac{\Delta_{t}}{h_{1}^{2}(1+\mathrm{k})}
$$

Where: $\Delta t=\left(\rho_{s}-\rho_{w}\right) / \rho_{w}$, relative weight of tube $\left[\mathrm{kg} / \mathrm{m}^{3}\right]$;

The above equation can be simplified for tubes placed parallel to the axis of a breakwater with their crest below or at SWL to produce the dimensionless stability relation:

$$
\frac{\mathrm{H}_{\mathrm{S}}}{\Delta_{t} b}<1
$$

Filling percentage is not include in the formula, but from the height and width measurements of the geotextile tubes used in the physical modeling, which were used to determine the above stability formula it is calculated that the tubes were filled to approximately $90 \%$.

\subsection{Safety factors of stability on geotextile tubes according to Oh and Shin (2006)}

It was based on two-dimensional limit equilibrium theory. To simplify the two-dimensional analysis, gravity weight of geotextile tube was calculated by equivalent rectangular shape in the effective height.

- $\quad$ Factor of safety against sliding, can be expressed by the following equation:

$$
\mathrm{SF}_{\text {sliding }}=\frac{\mathrm{F}}{\mathrm{P}_{\mathrm{h}}}=\frac{\mathrm{P}_{\mathrm{v}} \times \tan \phi^{\prime}}{\mathrm{P}_{\mathrm{W}} \times \mathrm{h}_{\mathrm{GT}}}
$$

Where: $P_{h}=$ horizontal force, $F=$ vertical force, $P v=$ overburden pressure and gravity weight of geotextile tube, $P_{w}=$ hydrodynamic pulsating load, $\mathrm{h}_{\mathrm{GT}}=$ effective height, $\varnothing^{\prime}=$ interface friction angle between geotextile and base sand.

Factor of safety against overturning, about the toe of an equivalent rectangular shaped tube, can be expressed by the following equation:

$$
\mathrm{SF}_{\text {overturning }}=\frac{\mathrm{M}_{\mathrm{R}}}{\mathrm{M}_{\mathrm{O}}}=\frac{\mathrm{P}_{\mathrm{v}} \times \frac{\mathrm{B}^{\prime}}{2}}{\mathrm{P}_{\mathrm{W}} \times \frac{\mathrm{h}_{\mathrm{GT}}}{2}}
$$


Where: $\mathrm{B}^{\prime}=$ width of an equivalent rectangular shaped tube.

- $\quad$ Factor of safety against bearing capacity failure, can be determined by following equation:

$$
\mathrm{SF}_{\text {bearing capacity }}=\frac{\mathrm{Q}_{\mathrm{u}}}{\mathrm{Q}_{\mathrm{a}}}=\frac{\mathrm{cN}_{\mathrm{C}}+\left(\frac{1}{2}\right) \gamma_{\mathrm{S}} \mathrm{B}^{\prime} \mathrm{N}_{\gamma}}{\frac{\mathrm{P}_{\mathrm{W}}}{\mathrm{B}^{\prime-2 \mathrm{e}^{\prime}}}}
$$

Where: $\mathrm{c}=$ cohesion of the base soil, $\mathrm{Nc}$ and $\mathrm{Ny}=$ bearing capacity factors by the internal friction angle of saturated base soil, $\gamma_{s}=$ submerged unit weight of base soil, $e^{\prime}=\left(P_{w h} h_{G T}\right) / 3 F$ the eccentricity of the hydrodynamic pulsating load.

From the results of the two-dimensional stability analysis, the safety factor was decreased on increasing the filling ratio and significant wave height. The safety factor of bearing capacity varied linearly with filling ratio and significant wave height. However, safety factors of sliding and overturning exponentially decayed because of the relationship of equivalent width, effective height, and significant wave height.

\section{Equivalent rectangle}

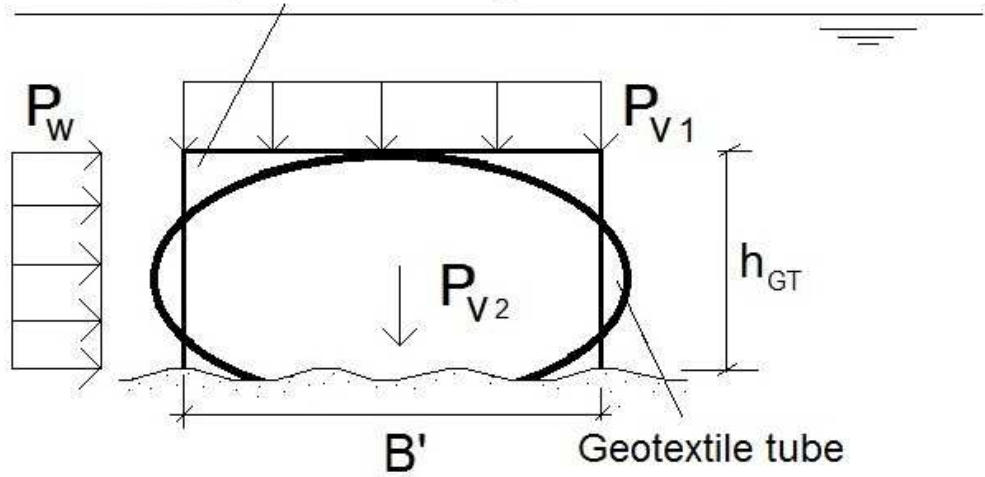

Fig 11: Analysis scheme two-dimensional hydraulic stability

\subsection{Formula of stability according to CUR 217 (2006)}

CUR 217 (2006) recommends using a very similar formula for calculating the limiting significant wave height to that prescribed by Pilarczyk (2000). It is more cautious, however, as it replace the width with that of the height of the geotextile tube. This has a significant effect on the allowed wave height as the width of an average tube is nearly twice that of his height.

CUR 217 (2006) states that the tube that receives the heaviest loading is the tube at the crest of the structure. A formula for a limiting significant wave height for the stability of a geotextile tube on the crest of a breakwater is given.

$$
\frac{\mathrm{H}_{\mathrm{S}}}{\Delta_{\mathrm{t}} \mathrm{D}_{\mathrm{K}}} \leq 1
$$

Where: $\mathrm{Hs}=$ significant wave height [m], Dk = height of geotextile tube (with tube perpendicular to wave direction), $\Delta \mathrm{t}=$ relative weight of tube or relative buoyant weight of tube.

Using the below formula gives an estimated $\mathrm{Hs}$ equal to the height of the tube $(\Delta \mathrm{t} \approx 1)$. The wave height from the above formula is the wave height at which the geotextile tube is expected to start moving. Note that filling percentage is not specified or used in this formula.

\subsection{S Formula of stability according to Van Steeg et al. (2011)}

Before the study done by Van Steeg et al. (2011), the behavior of geotextile tubes under wave loading was uncertain as no large modeling of geotextile tubes had been done.

To test the stability of sand-filled geotextile tubes under wave attack, large-scale physical models were tested in the Delta Flume of Deltares, with an approximate scale of $1: 2$ to $1: 4$. All failure resulted from sliding. Sand migration in tubes filled to less than $70 \%$ decrease stability, but is minimal in tubes with high filled to less than $70 \%$ decrease stability, but is minimal in tubes with high filling percentages (Van Steeg et al. 2011). 
As previous stability formulae are not clear on all the different possible input factors a new dimensionless stability relation was suggested that incorporates factors relative to hydraulic stability. The new derived stability relation for a single placed geotextile tube is:

$$
\frac{\chi \mathrm{H}_{\mathrm{S}}}{\Delta_{\mathrm{t}} \sqrt{\mathrm{BD}}(\mathrm{f} \cos \alpha+\sin \alpha)} \leq 0.65
$$

Where: $\mathrm{Hs}=$ significant wave height at limit of stability, $\Delta_{t}=$ relative density of density tube, $B=$ width of geotextile tube, $\mathrm{D}$ $=$ height of geotextile structure, $f=$ friction coefficient of the geotextile tube and supporting structure interface, $\alpha=$ slope of the supporting structure, $X=$ reduction factor for lost energy due to overtopping.

Placing two geotextile tubes behind each other did not increase the hydraulic stability. The reason for this was ascribed to the hydrostatic pressure caused by the water trapped between the two tubes and the hydrodynamic water pressures caused by the wave action, which caused the land-side tube to shift. It is recommended that the same formula be used as for a singly place geotextile tube.

\section{ANALYSIS OF GEOTEXTILE ENCAPSULATED SAND ELEMENTS}

Geo-systems, such as geotextile bags or geotextile tubes are elements that constitute a good alternative structures for coastal defense in relation to the type of material, its execution time and cost. However there are a number of disadvantages regarding the use of geotextile elements, which give rise to approach some questions like: are they suitable materials to withstand the weather and waves?, come from reliable calculation methods?, are they readily degradable?, and how is its visual impact? Many questions how are you could be grouped into: are they effective in all cases? Or is there any limitation on its use? To answer these questions we have relied on two contrasting examples and formulation stability calculation of previous sections.

\subsection{Case study 1: Geotextile tubes on the beach Young-Jin (Korea)}

Oh and Shin (2006) analyzed the behavior of geotextile tubes immersed as a solution to a problem of erosion on the beach Young-Jin, at the east coast of Korea, aggravating the problem when the waves reached a significant wave height of $4 \mathrm{~m}$ in winter.

Based on the results of analysis of stability and hydraulic test scale model, in which two lines of geotextile tubes were used. Was determined to be more stable and effective than other approaches proposed design. Subsequently, as a result of the execution of the work, the shoreline moved between 2.4 and $7.6 \mathrm{~m}$ to the sea by the accumulation of sediment with geotextile tubes.

\section{Site plan of Young-Jin beach}

Sumerged geotextile tube breakwaters
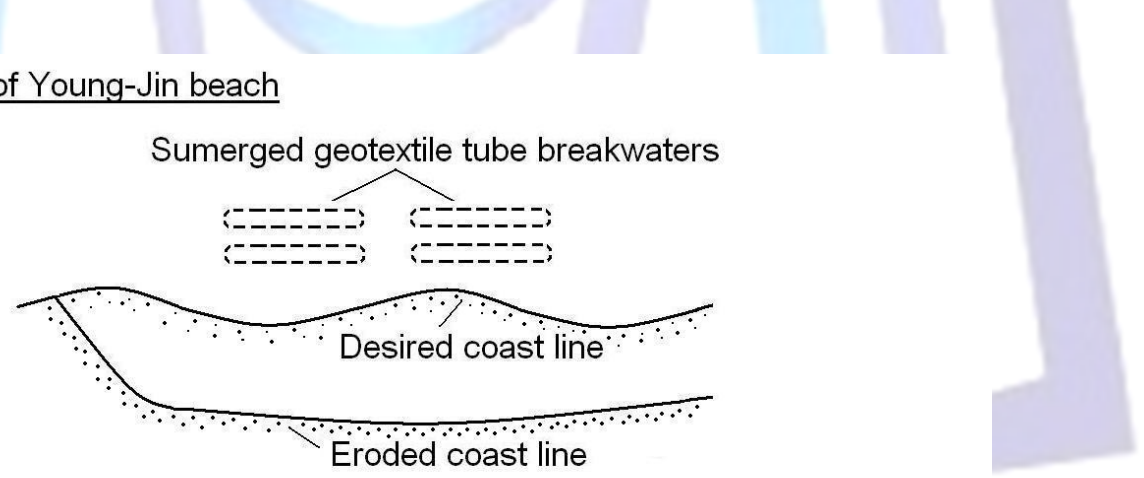

$\underline{\text { Cross section }}$

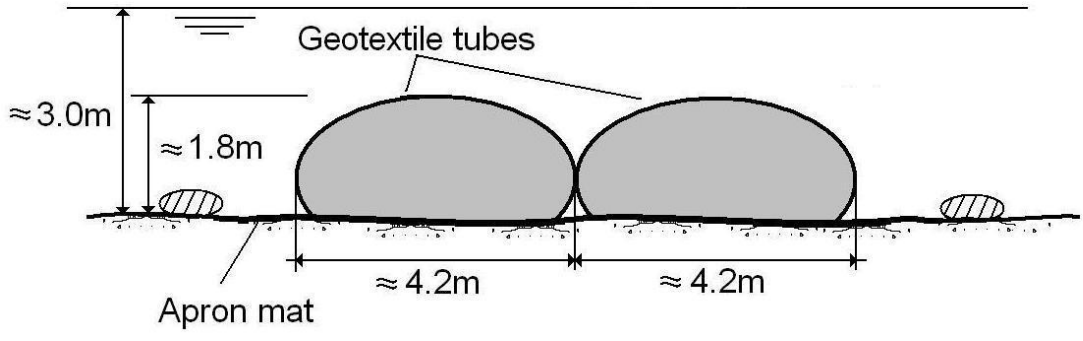

Fig 12: Site plan and crosssection of the beachYoung-Jin(Korea) 


\subsection{Case study 2: Geotextile tubes on the coast of Jumeirah (Dubai)}

On the other hand, in the northern part of the coast of Jumeirah, in the emirate of Dubai, Weerakoon et al. (2003) used geotextile tubes as coastal defense solution. Recommendations based on experience were mainly that the placement of geotextile tubes offshore only be possible with a very calm surf and wave heights exceeding 40-50 cm made it difficult to keep the filling ports in position during filling operation.

A significant reduction of wave energy to enter the inshore area with small waves and under very low tide was observed. However, it turned out that the width of the pipe crown was insufficient compared to the wavelengths of the high waves.

Erosion was a significant problem for structures with geotextile tubes. There was a strong erosion on both sides of the geotextile tubes. Due to breakage of the wave and current-driven surf on the outside. Because of large tubes were more vulnerable to a complete breakdown due to the break anywhere along its length.

And in general, geotextile tubes were not visually attractive structures, since the remodeling of the tubes after changing the sand and deformations in the seabed tended to lose the aesthetic quality of the structure significantly and growth seaweed, so that the tubes did not improve their appearance.

\section{Site plan of Jumeirah Open beach}

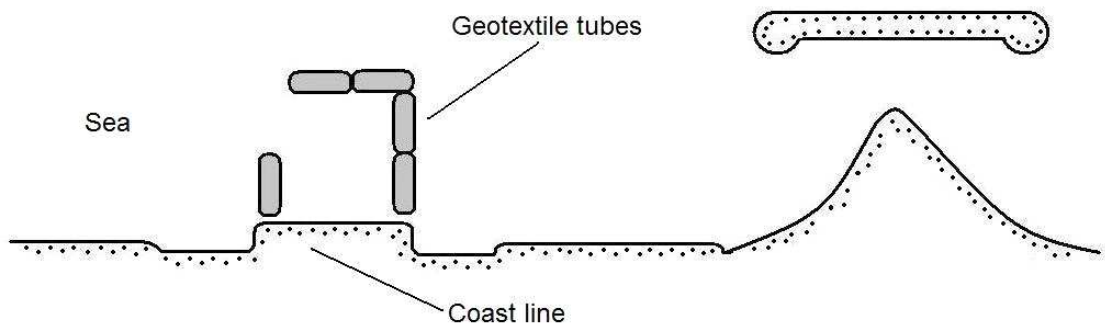

$\underline{\text { Cross section }}$

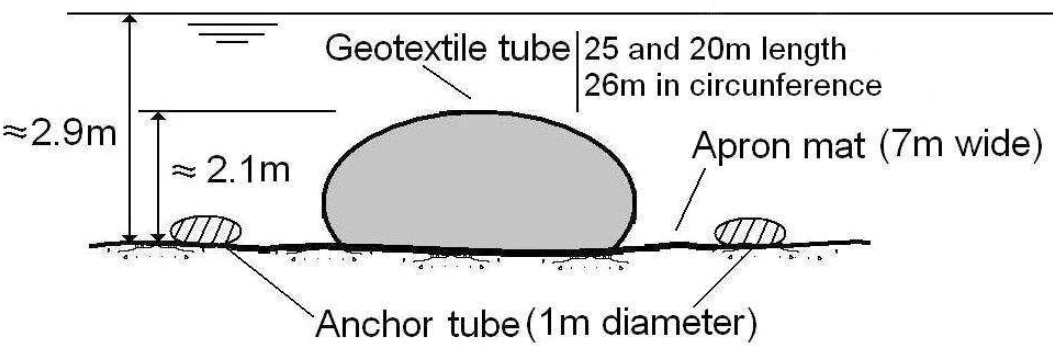

Fig 13: Site plan and crosssection of Jumeirah Open beach(Dubai)

\subsection{Comments on methods stability}

Considering the stability methods listed above, by analyzing the following is performed:

- $\quad$ The formula stability Pilarczyk (1996) for geotextile bags directly exposed to waves is applicable to heights of less than $2 \mathrm{~m}$ wave. This limitation is only possible in protected coastal areas with little agitation or residual swell.

- Pilarczyk (2000) considers the critical wave height equal to the theoretical diameter of the tube. Similarly this restriction with respect to the wave height limits its location in coastal areas.

- $\quad$ Stability formulas Oumeraci et al. (2003) derived from laboratory tests, so it should only be applied in the same conditionin which the test is performed.

- $\quad$ And the stability formula Recio and Oumeraci (2009) can only be applied to one type of geotextile bag.

Therefore, stability methods are not applicable fo rall wave heights for all geotextilebags. Being limited its location on the coast protected areas. 


\section{CONCLUSIONS}

Elements of sand filled geotextile can be considered more as a complement to coastal protection systems, which as an alternative.

Analytical and / or experimental models to simulate geosystems performance have been developed and calibrated with results of tests performed by different investigators. Providing only indicative results.

The degradation due to ultraviolet sunlight, abrasion by sand and rubble rupture by water or vandalism transmitted is commonly cited as the main concerns of material failures. Having a different opinion on whether the elements of geotextile require additional protection against UV degradation, vandalism and general wear. Observation and monitoring of projects have provided information regarding the suitability and life expectancy of the elements of geotextile for different coastal applications.

Furthermore, it was found that the procedures for placing geotextile elements require calm conditions, due to uncertainty about their behavior under the action of strong waves.

The durability of the material and the long-term behavior of geotextile elements remain the points of interest. The systematic monitoring of projects (including failure-cases) and data evaluation and laboratory prototype can provide useful information for verification and refinement of the design criteria.

Even today some doubts raised about the reliability of design methods in heavy storm conditions. So it will be necessary to improve design methods and increase their practical experience in various load conditions.

\section{ACKNOWLEDGMENTS}

The first author gratefully acknowledges to CEDEX and ETSICCP-UPM. It would not have been possible to carry out this work without the participation of the members from Centre for Harbours and Coastal Studies, CEDEX.

\section{REFERENCES}

[1] Bezuijen, A. and Pilarczyk, K. W. 2012. Geosynthetics in hydraulic and coastal engineering: filters, revetments and sand filled structures. In Proceedings of EuroGeo 5, Valencia, 65-80.

[2] Chu, J., Guo, W. and Yan, S. W. 2011. "Geosynthetics tubes and geosynthetic mats: analysis and applications". Geothecnical Engineering Journal of the SEAGS \& AGSSEA, 42(1), ISSN 0046-5828.

[3] CUR 2006. CUR217: Ontwerpen met geotextielezandelementen, Stichting CUR, Gouda.

[4] Dassanayake, D.T. 2013. Experimental and numerical modelling of the hydraulic stability of geotextile sand containers for coastal protection. Doctoral Thesis. FakultätArchitektur, Bauingenieurwesen und Umweltwissenschaften der echnischenUniversitätCarolo-Wilhelmina zuBraunschweig.

[5] Gutman, L.1979. Low-cost shoreline protection in Massachusets, ASCE, Coastal Structures.

[6] Heibaum, M. 1999. "Coastal scour stabilization using granular filter in geosynthetic nonwoven containers". GeotextilesandGeomembranes, 17, No. 5-6,341-352.

[7] Kobayashi, N. and Jacobs, B. 1985. "Stability of Armor Units on Composite Slopes." Journal Waterway, Port, Coastal, Ocean Eng., 111(5), 880-894.

[8] Klusman,. 1998. Civil Engineering in the Oceans VI. Proceedings of the International Conference, October 20-22, 2004, Baltimore, Maryland.

[9] Leshchinsky, D. y Leshchinsky, O. 1996. "Geosynthetic confined pressurized slurry (GeoCoPS): Supplemental notes for version 1.0". Report TR CPAR-GL-96-1, US Army Engineer Waterways Experiment Station.

[10] Liu, G. S. 1981. "Design criteria of sand sausages for beach defenses. XIX IAHR. Congress, New Delhi, India, 95-97.

[11] Lawson, C. R. 2008. "Geotextile containment for hydraulic and environmental engineering". Geosynthetic International, 15(6), 384-427.

[12] Oh, Y. I. and Shin, E. C. 2006. "Using submerged geotextile tube structures in the protection of the E. Korean shore". Coastal Engineering, 53, 879-895.

[13] Oumeraci, H., Hinz, M., Bleck, M. y Kortenhaus, A. (2003). "Sand-filled geotextile containers for shore protection", COPEDEC VI, Colombo, Sri Lanka.

[14] PIANC, 2011. The application of geosynthetics in waterfront areas. PIANC, 113.

[15] Pilarczyk, K. W., 1990. Coastal protection. A.A. Balkema Publisher, Rotterdam.

[16] Pilarczyk, K. W., 1996. Geotextile systems in coastal engineering. An overview. In Proceedings of 25th Conference on Coastal Engineering, ASCE, 2114-2127. 
[17] Pilarczyk, K. W., 2000. Geosynthetics and Geosystems in Hydraulic and Coastal Engineering. A. A. Balkema, Rotterdam.

[18] Plaut, R.H.andKlusman, C.R., 1999. Two-dimensional analysis of stacked geosynthetic tubes on deformable foundations. Thin-Walled Structures 34, 179-194.

[19] Recio-Molina, J. and Yasuhara, K., 2005. "Stability of modified geotextile wrap-around revetments (GWR) for coastal protection”. Geosynthetics International, 12(5).

[20] Recio-Molina, J. and Oumeraci, H., 2009. "Processes affecting the hydraulic stability of coastal revetments made of geotextile sand containers". Coastal Engineering, 56, 260-284.

[21] Steeg, P. Van; Vastenburg, E.; Bezuijen, A.; Zengerink, E., and de Gijt, J., 2011.Large-scale physical model tests on sand-filled geotextile tubes and containers under wave attack. Proceedings of 6th International Conference on Coastal Structures, Yokohama.

[22] Weerakoon, S.; Mocke, G. P.; Smit, F., and Al Zahed, K., 2003. "Cost effective coastal protection works using sand field geotextile containers. CODEPEC VI, Colombo, Sri Lanka.

[23] Wouters, J., 1998. Open Taludbekledingen; stabiliteit van geosystems (Stability of geosystems). Delft Hydraulics, report H1930, Annex 7 (in Dutch).

\section{Author' biography with Photo}

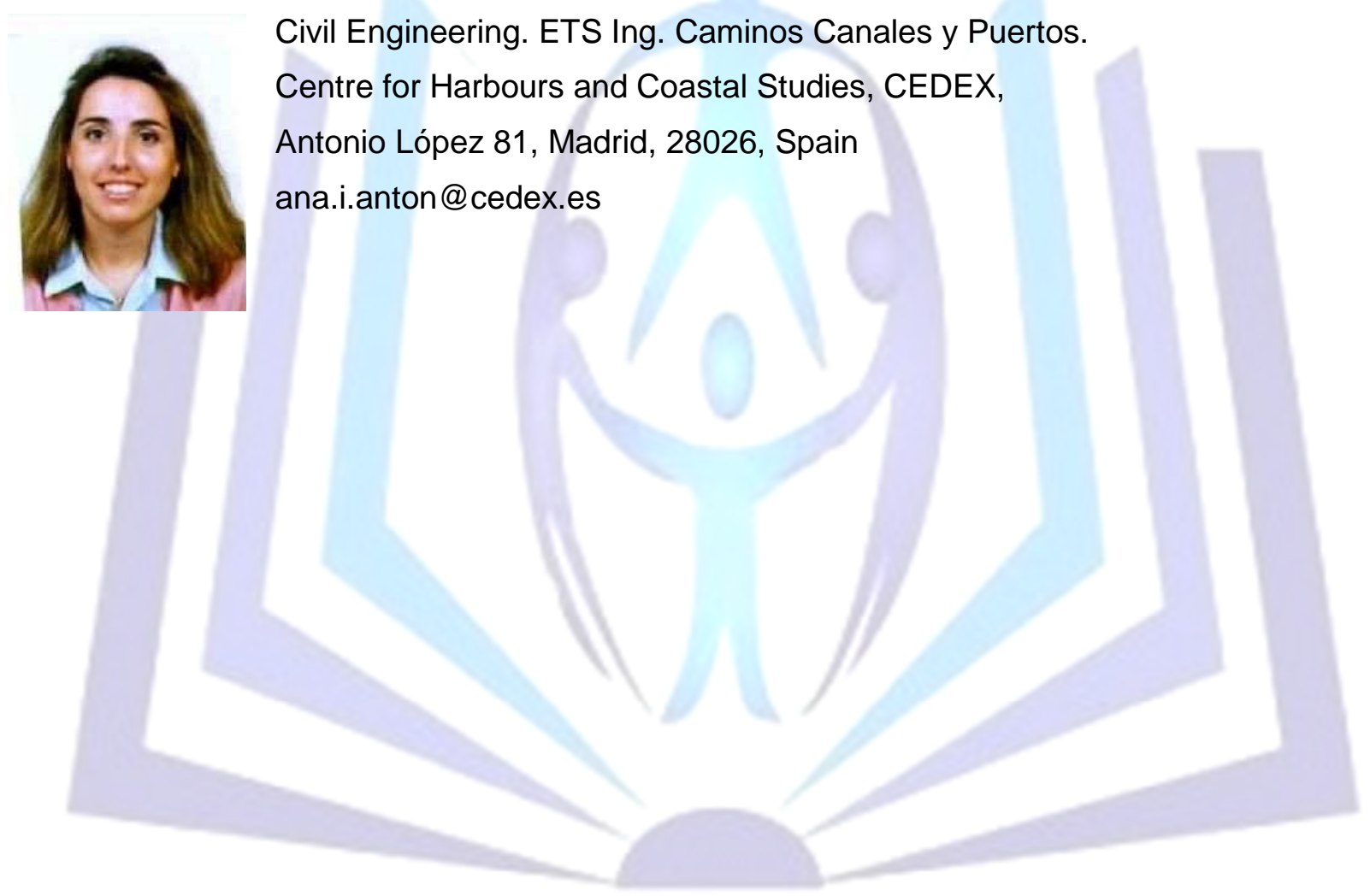

